\title{
N-Donor Functionalized Acetylacetones for Heterobimetallic MOFs - The Next Episode: Trimethylpyrazoles
}

Steven van Terwingen ${ }^{1, *}$, and Ulli Englert ${ }^{1,2}$

${ }^{1}$ Institute of Inorganic Chemistry, RWTH Aachen University, Landoltweg 1, 52074 Aachen, Germany;

${ }^{2}$ Key Laboratory of Materials for Energy Conversion and Storage, Institute of Molecular Science, Shanxi University, Taiyuan, Shanxi 030006, People's Republic of China.

* Corresponding author: steven.vanterwingen@ac.rwth-aachen.de 
Abstract: While metal-organic frameworks (MOFs) have been investigated intensively throughout the last decades, only a fraction of the published articles on MOFs feature heterobimetallic structures. Combining two metallic centers in a rigid framework could lead to interesting effects, such as magnetic coupling, collaborating fluorescence or catalytic properties; however, its synthesis is more sophisticated than for monometallic MOFs. We utilize ditopic ligands whose coordination sites differ in their Pearson hardness (HSAB). This enables a stepwise selective formation of heterobimetallic MOFs: first, a monometallic building block is synthesized. In a second step the framework can be constructed by crosslinking with a second metal ion.

In this work we present our most recent ligand candidate: 3-(1,3,5-trimethyl$1 H$-pyrazol-4-yl)acetylacetone. Its synthesis is straightforward and inexpensive. The $\mathrm{O}, \mathrm{O}^{\prime}$ coordination was accomplished with a variety of hard cations like $\mathrm{Fe}^{\mathrm{III}}$ or $\mathrm{Ga}{ }^{\mathrm{IIII}}$. First crosslinking attempts with $\mathrm{N}$ coordination of the $\mathrm{Fe}^{\mathrm{III}}$ building block to $\mathrm{Ag}^{\mathrm{I}}$ leads to a one-dimensional coordination polymer with high porosity.

Keywords: MOFs; coordination chemistry; crystal engineering 


\section{Introduction}

We aim for the stepwise and selective synthesis of heterobimetallic metal-organic frameworks (MOFs). For that purpose we utilize ditopic ligands which donor sites differ in Pearson hardness [1]. Here we present a trimethylpyrazolyl substituted acetylacetone to construct a heterobimetallic coordination polymer.

$\mathrm{Cu}^{\mathrm{I}}, \mathrm{Ag}^{\mathrm{I}}, \mathrm{Hg}^{\mathrm{II}}$

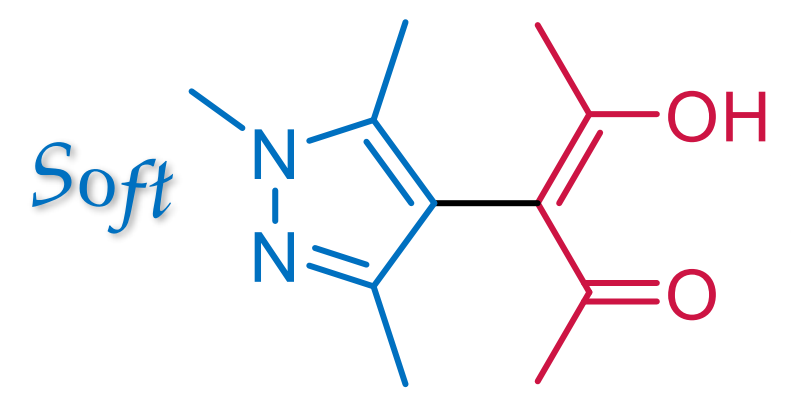

HARD Fe ${ }^{I I I}, \mathrm{Ga}^{\mathrm{III}}, \mathrm{Yb}^{\mathrm{III}}$
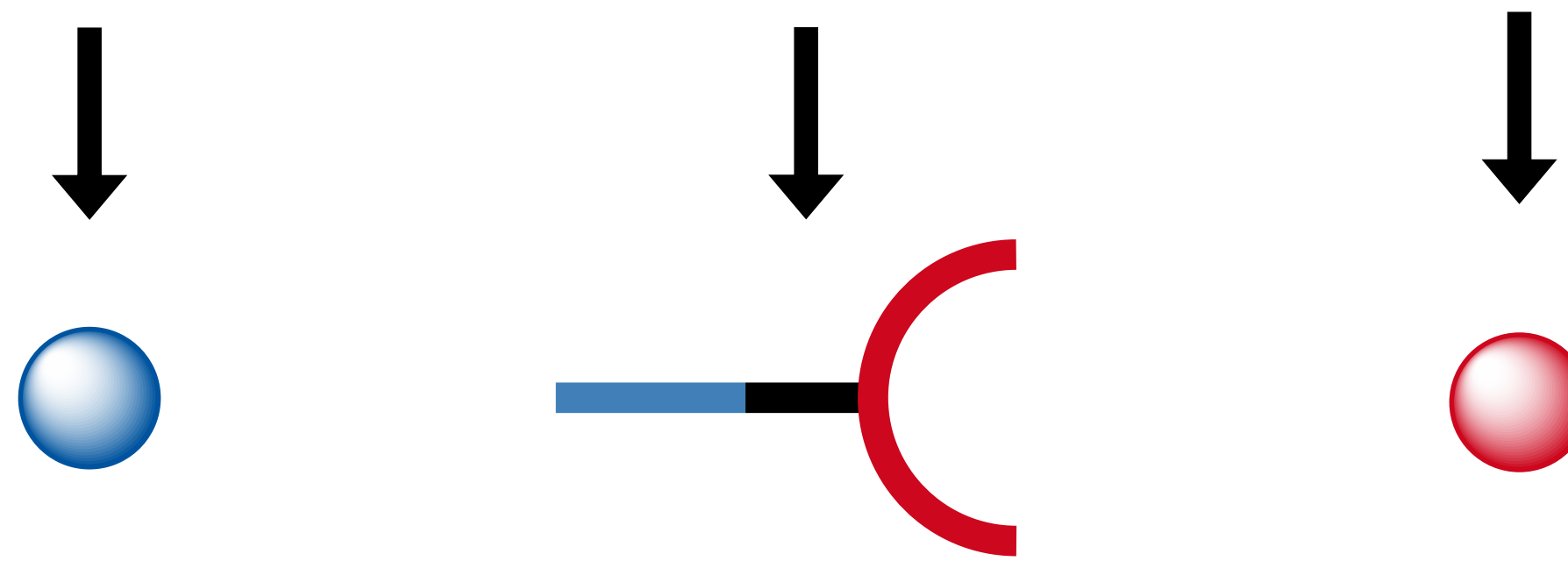

Crystals 


\section{Motivation}

Stepwise synthesis of a heterobimetallic MOF achieved with a ditopic ligand:

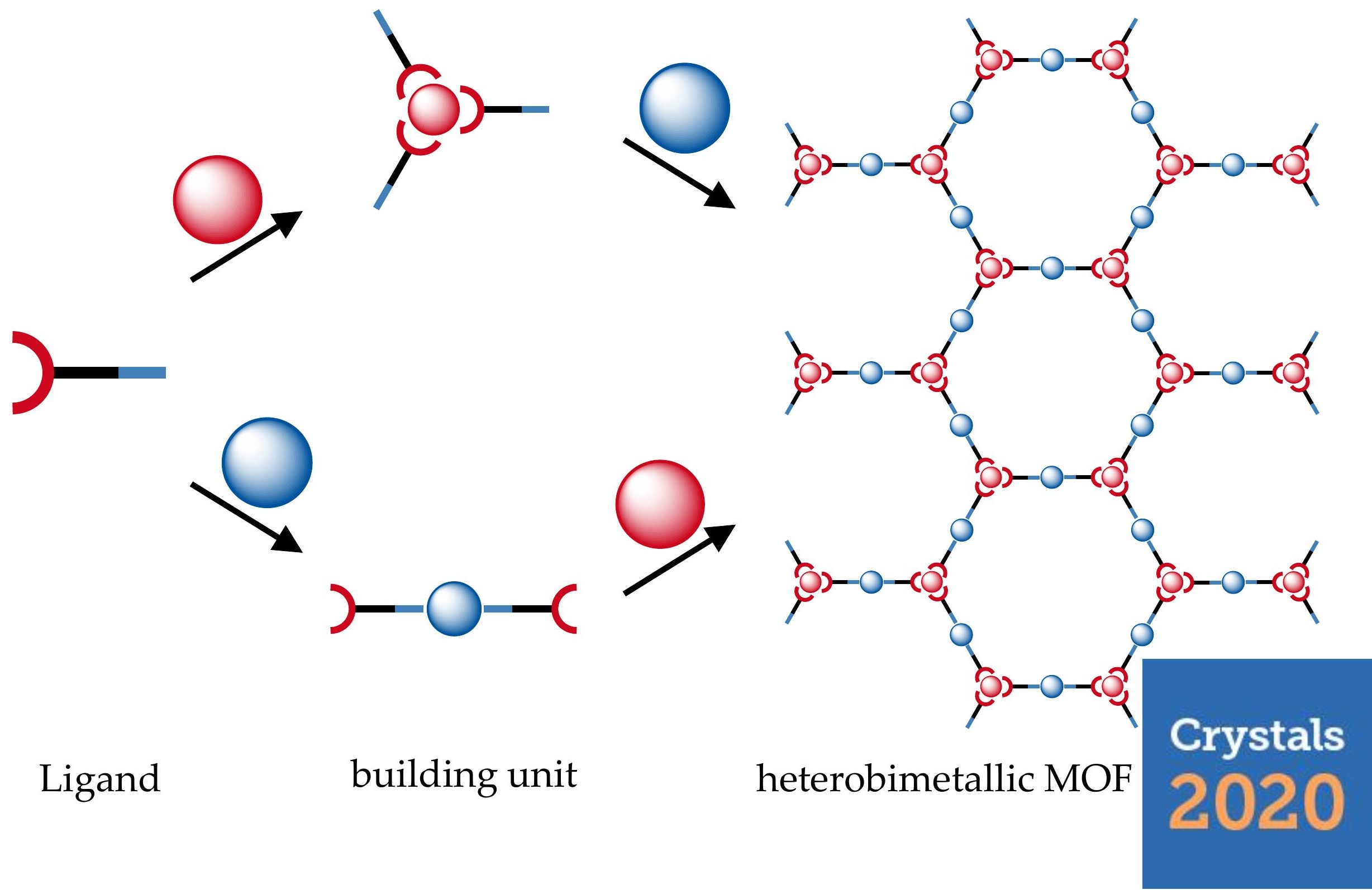




\section{Motivation}

There are various properties of these MOF's which are worth investigating (bottom left). Post-modification and/or thermal decomposition can also lead to complex systems with interesting features, e.g. one example of our group shows catalytic properties for the $\mathrm{N}_{2} \mathrm{O}$ conversion to the elements after thermal decomposition of an $\mathrm{Yb}^{\mathrm{III}} / \mathrm{Ag}^{\mathrm{I}} \mathrm{MOF}$ (bottom right) [3]:

Analysis of the MOF's:

- topology[2]

- catalytic properties[3]

- luminescence

- gas storage properties

- magnetism

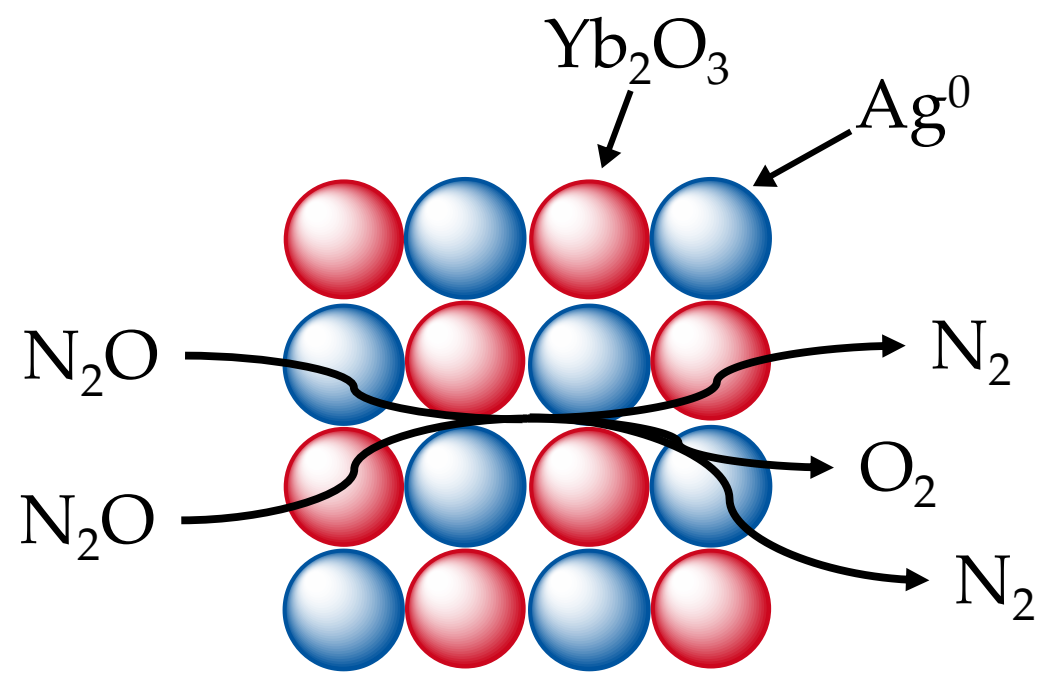

heterogeneous solid[3]

$2 \mathrm{~N}_{2} \mathrm{O} \stackrel{\mathrm{Ag}^{0}}{\longrightarrow} 2 \mathrm{~N}_{2}+\mathrm{O}_{2}$ 


\section{Results - Synthesis}

Crosslinking with $\mathrm{Fe}^{\mathrm{III}} / \mathrm{Ag}^{\mathrm{I}}$ leads to a $1 \mathrm{D}$ polymer $\mathbf{1}$ :

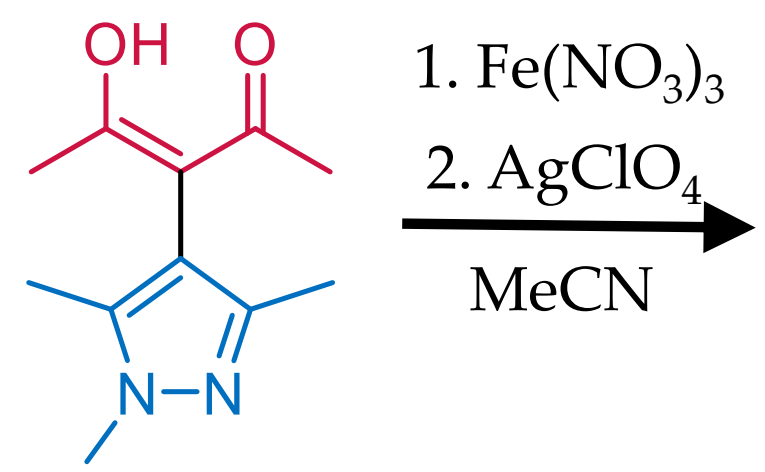

\begin{tabular}{lc}
\hline composition & $\mathrm{C}_{560} \mathrm{H}_{768} \mathrm{Ag}_{16} \mathrm{Fe}_{16} \mathrm{~N}_{112} \mathrm{O}_{96}$ \\
Crystal system & orthorhombic \\
Space Group & $F d d 2$ \\
$a / \AA$ & $53.3047(8)$ \\
$b / \AA$ & $70.5917(12)$ \\
$c / \AA$ & $15.1465(3)$ \\
$V / \AA$ & $56994.3(17)$ \\
$Z$ & 2 \\
$\theta_{\min / \text { max }}\left(\mathrm{Cu}-\mathrm{K}_{\alpha}\right)$ & $2.08 / 58.2$ \\
total/unique/observed refl. & $144676 / 19245 / 10675$ \\
$R_{1}[I>2 \sigma(I)]$ & $12.92 \%$ \\
wR $R_{2}[$ all data] & $22.75 \%$ \\
$S$ & 0.962 \\
\hline
\end{tabular}

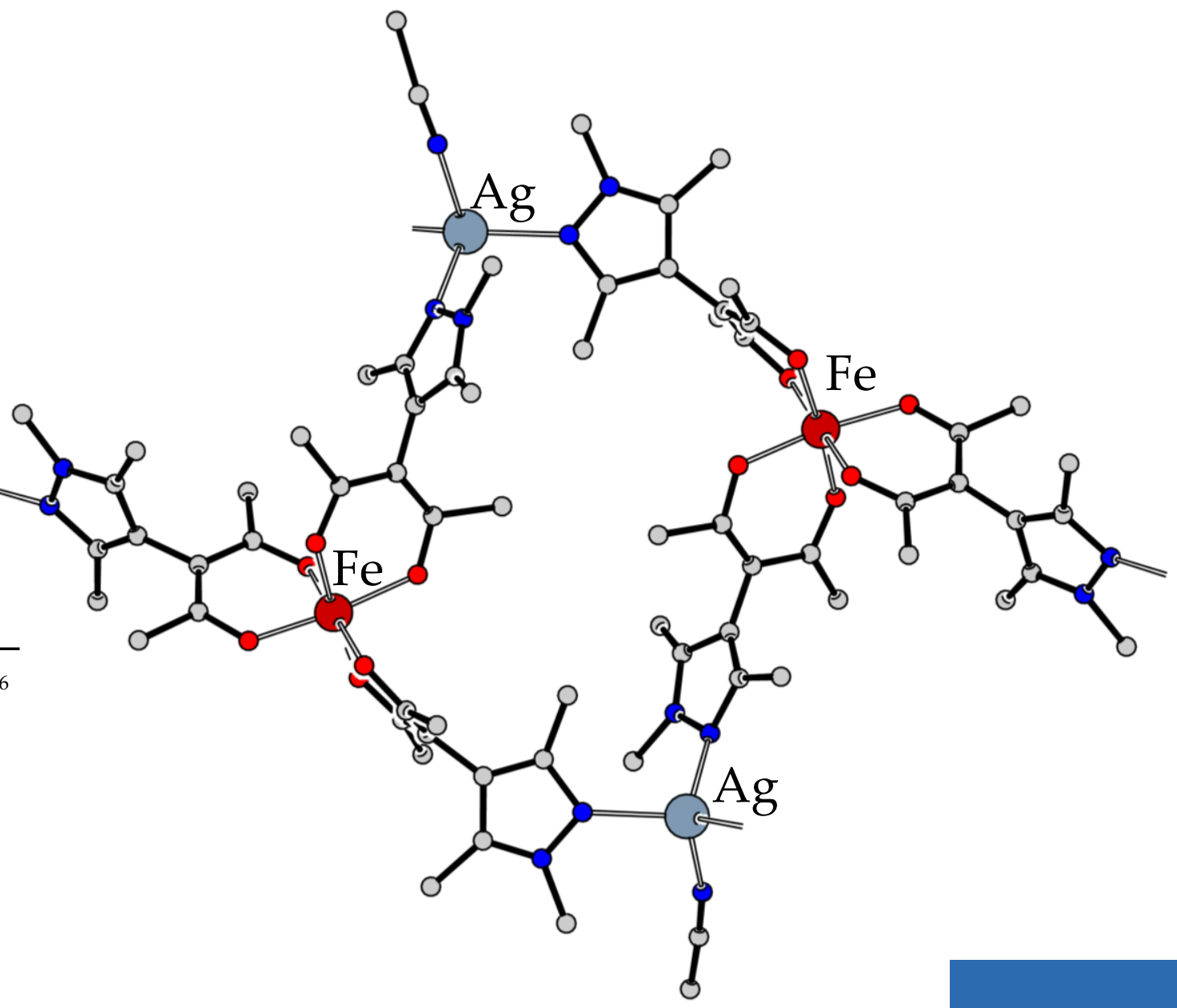

1

Crystals 2020 


\section{Results - Topology}

The chain polymer propagates in a wave-like fashion:

View from the $a b$ plane:

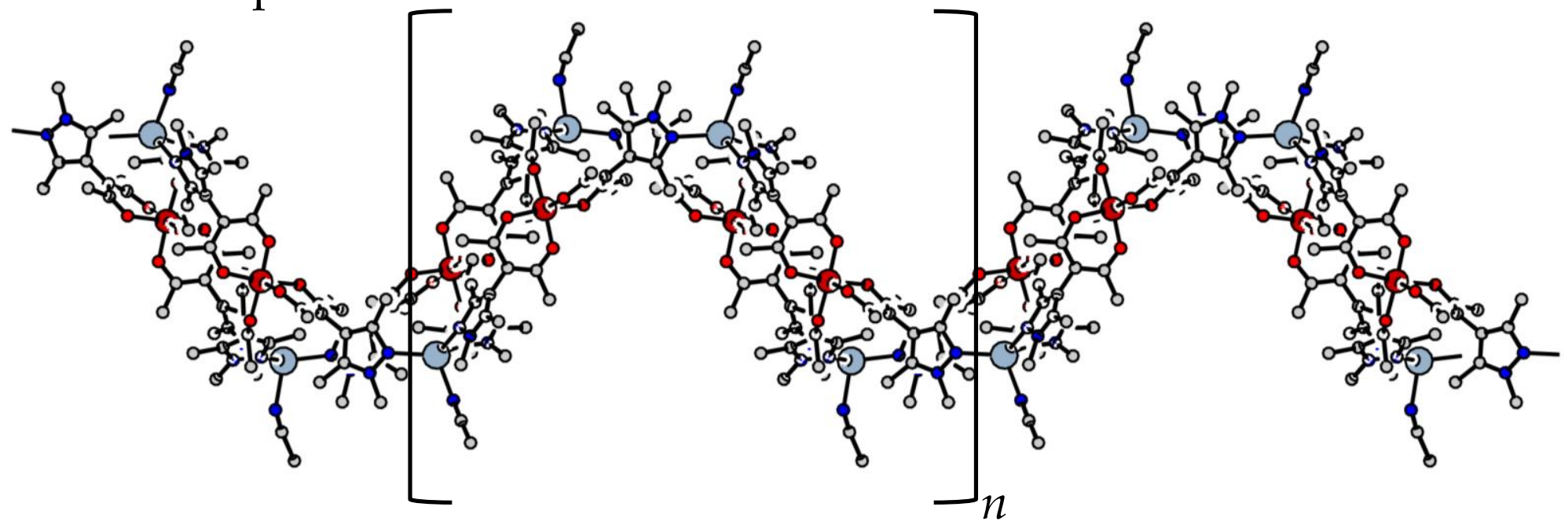

The chains exhibit ligands as crosslinkers between two strands, forming a ladder-like chain:

View from the ac plane:

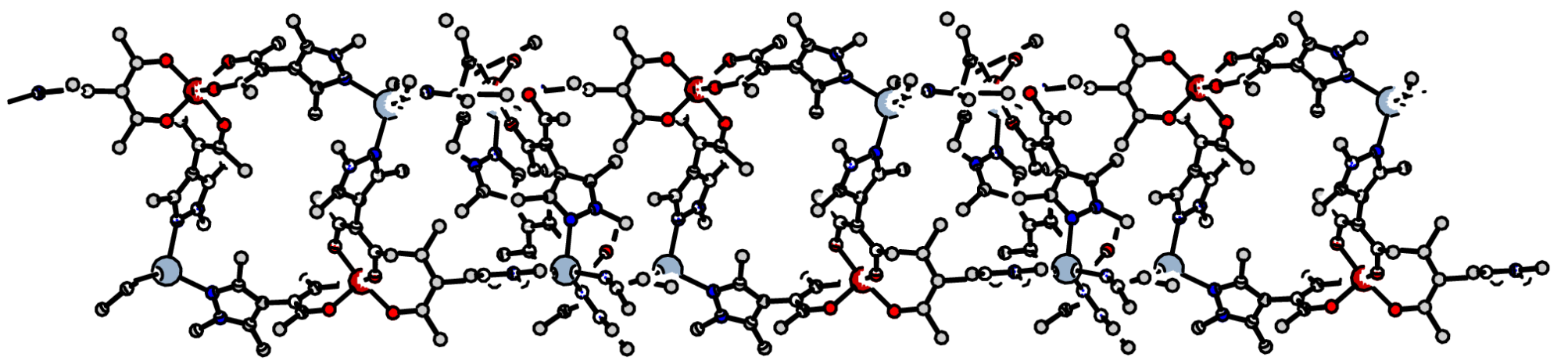




\section{Results - Topology}

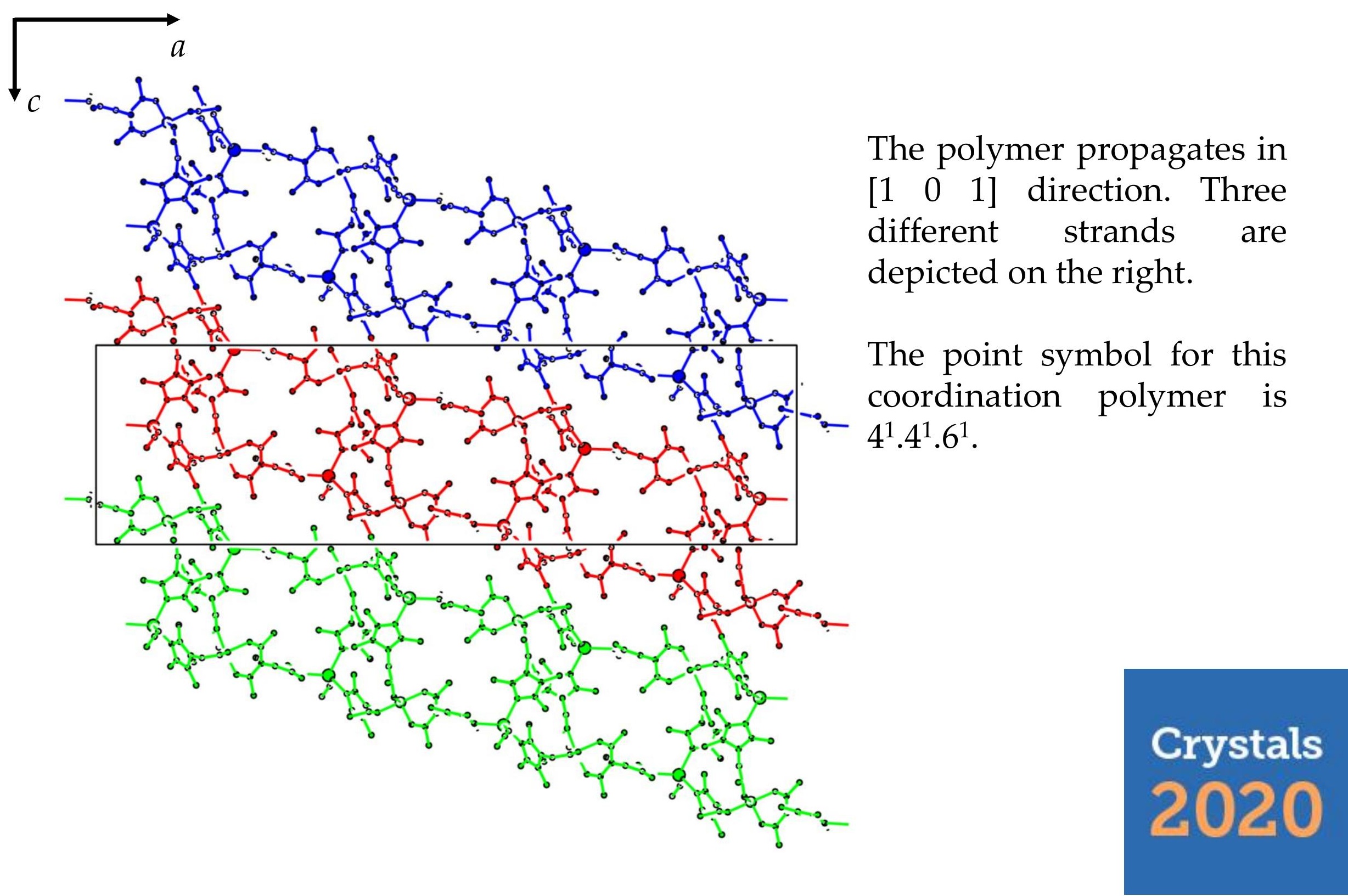




\section{Results - Topology}

simplified representation of the 1D polymer:

There are no meaningful interactions between two of the ladder-like chains. The shortest distance between them
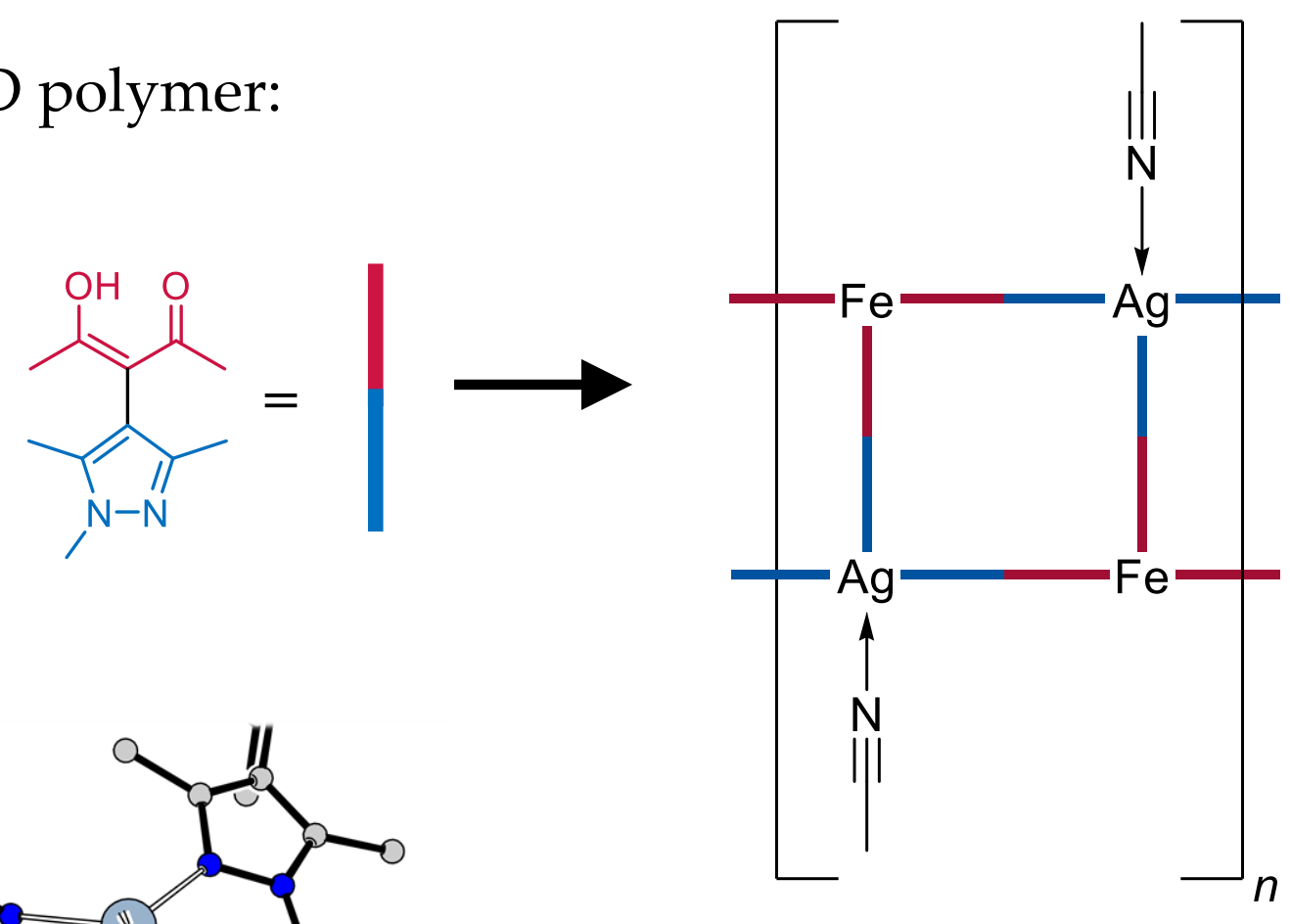
amounts to $2.7 \AA$ :

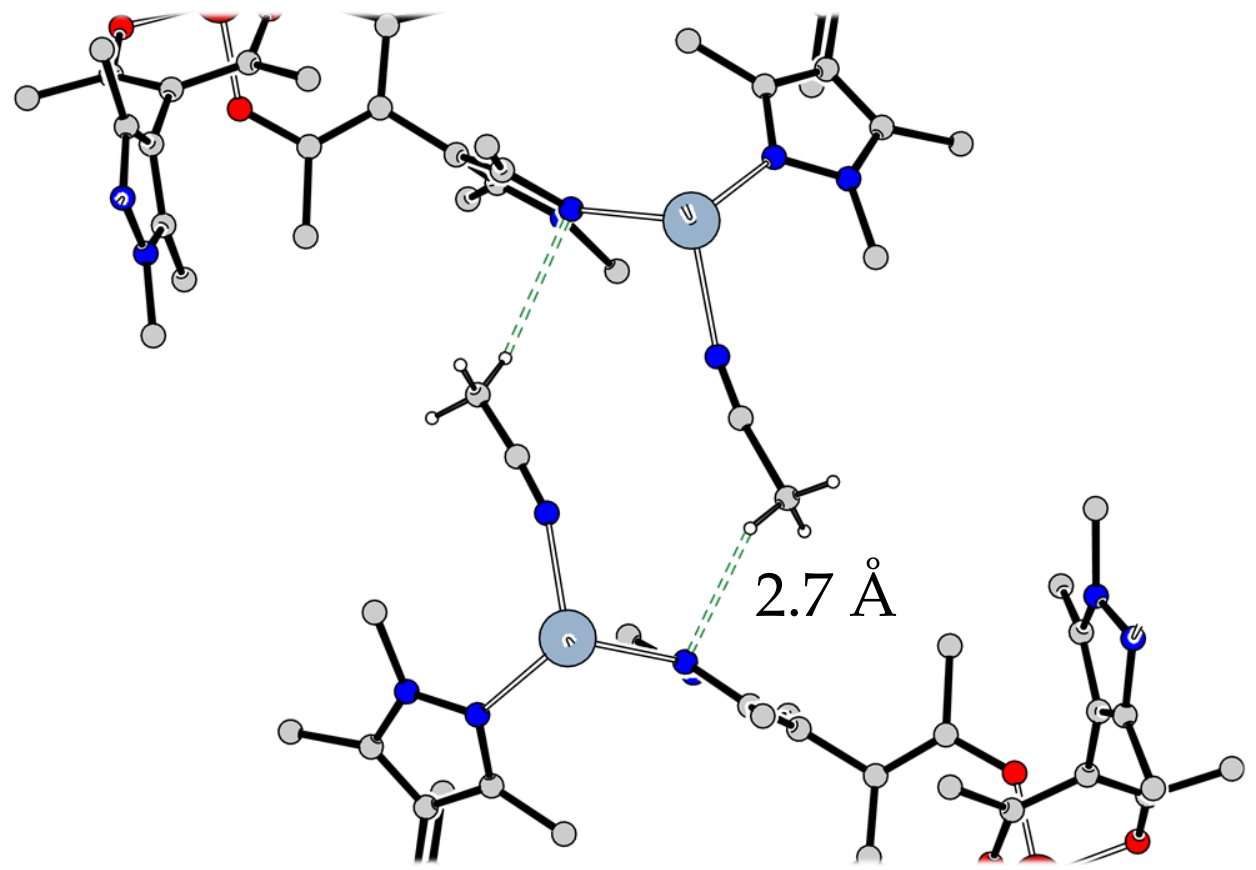

Crystals 


\section{Results - Topology}

There are huge solvent accessible voids in the structure. The PLATON SQUEEZE $[4,5]$ procedure was used to determine size and electron count of the voids:

\begin{tabular}{lc}
\hline Cell volume $/ \AA^{3}$ & $56994.3(17)$ \\
Void volume $/ \AA^{3}$ & 30200 \\
percent void of cell & $53.1 \%$ \\
electron count & 9600 \\
packing index & $67.4 \%$ \\
electron count $-32 \mathrm{ClO}_{4}^{-}$ & 8250 \\
amount & of $\mathrm{MeCN} / \mathrm{H}_{2} \mathrm{O}$ \\
Volume $^{*}$ per Atom $/ \AA^{3}$ & 260 \\
\hline
\end{tabular}
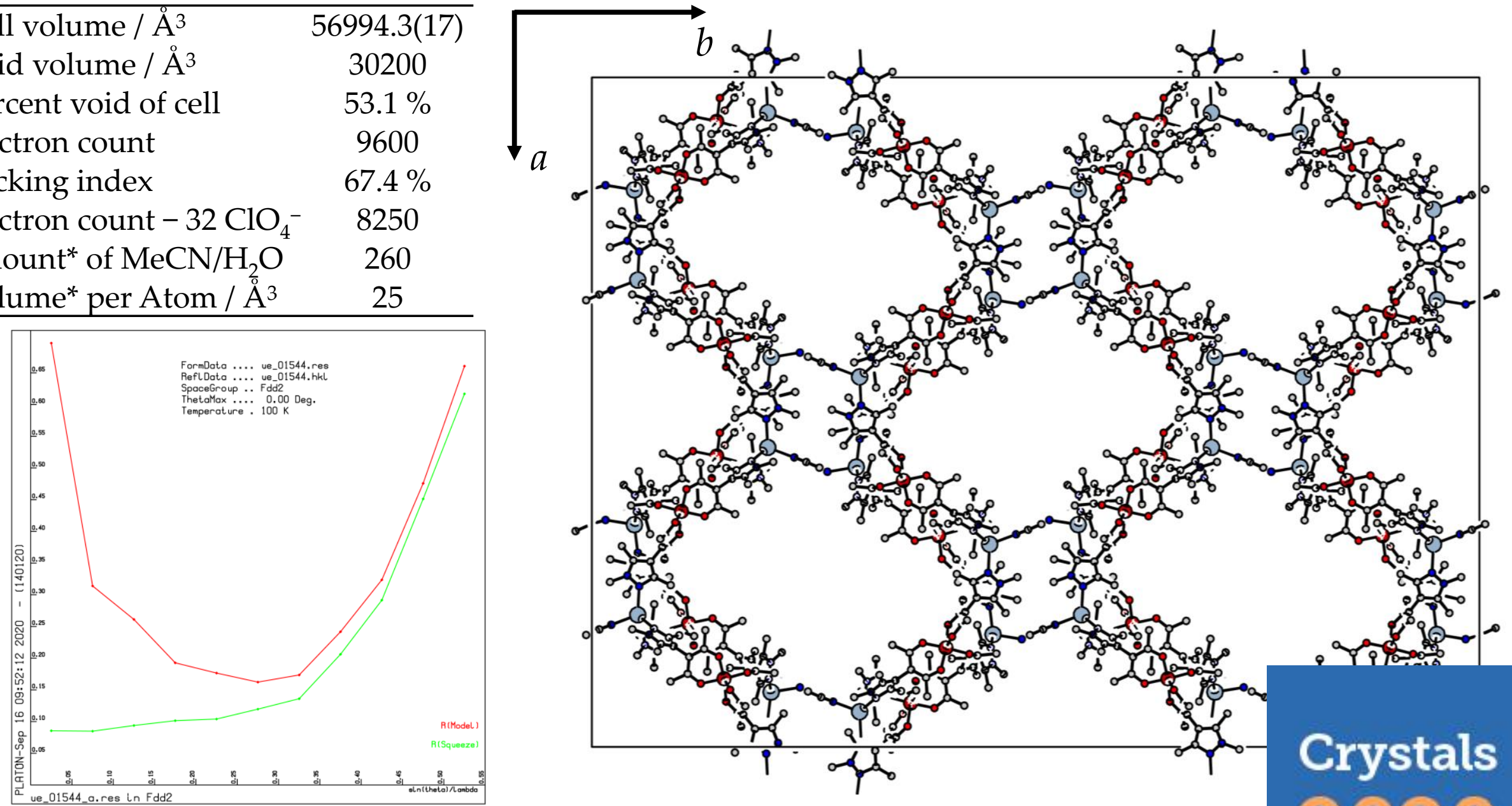

[4] A. L. Spek, Acta Crystallogr. 2009, D65, 148-155.

[5] A. L. Spek, Acta Crystallogr. 2015, C71, 9-18. 


\section{Conclusions}

The potential of the novel ligand featuring a pyrazolyl group shows promising results for the stepwise synthesis of heterobimetallic MOFs. The coordination polymer with $\mathrm{Fe}^{\mathrm{III}} / \mathrm{Ag}^{\mathrm{I}}$ shows large solvent-filled voids, created by the wave-like propagation of the one-dimensional chains in [lllll $\left.\begin{array}{lll}1 & 1\end{array}\right]$ direction.

Further investigation of the properties is planned. Thermal decomposition and, afterwards, screening for catalytic properties will be performed. The anion of the $\mathrm{Ag}^{\mathrm{I}}$ salt will be altered, to investigate ist effects on the related structure. Also, the choice of different metals, e.g. $\mathrm{Cu}^{\mathrm{II}}$, could lead to interesting effects and different topologies.

If you have any questions please do not hesitate to write me an e-mail: steven.vanterwingen@ac.rwth-aachen.de 


\section{Acknowledgements}

An RWTH fellowship to SvT is gratefully acknowledged. The help of all members of the AKS and the Institute of Inorganic Chemistry, RWTH Aachen University is greatly appreciated. 